\title{
How Do the Recent Major Randomized Controlled Trials Inform Best Use of the Novel Glucose-Lowering Agents?
}

\author{
Louisa Sukkar ${ }^{a, b}$ Tamara Young ${ }^{a}$ Meg J. Jardine ${ }^{a, b}$

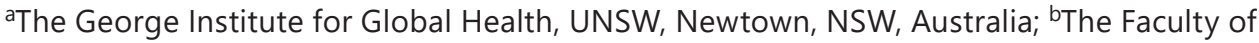 \\ Medicine and Health, The University of Sydney, Sydney, NSW, Australia
}

\section{Keywords}

Type 2 diabetes - Cardiovascular disease - Sodium-glucose co-transporter 2 inhibitors . Glucagon-like peptide-1 receptor agonists

\begin{abstract}
Background: Type 2 diabetes mellitus (T2DM) is frequently associated with the development of cardiovascular disease and chronic kidney disease (CKD). Some newer glucose-lowering agents confer both cardiac and kidney benefits, as supported by robust data from recent high-quality randomized controlled trials. The decision-making process when selecting glucose-lowering medications for T2DM now extends beyond glycaemia and metabolic effects, and towards additional benefits such as prevention of other complications. Summary: We review the evidence for efficacy in 3 new classes of medication for T2DM and additionally discuss relevant safety issues when considering optimal agents. Key Messages: Clinicians have multiple efficacy and safety factors to consider when selecting agents for glucose lowering in T2DM, and this should help direct individualized selection of pharmacotherapy for patients. New medications offer an opportunity to prevent cardiac and renal complications in people with T2DM.

(C) 2020 The Author(s)

Published by S. Karger AG, Basel
\end{abstract}

\section{Introduction}

Type 2 diabetes mellitus (T2DM) is a global health problem, with an estimated 451 million persons affected worldwide [1]. CKD, affecting around $10 \%$ of people, is a common complication and is associated with increased morbidity and mortality [2]. T2DM and CKD

Drs. Louisa Sukkar and Tamara Young are equal first authors.

Meg J. Jardine, Program Head

Innovation and Kidney Research

The George Institute for Global Health

Newton, 1 King Street, NSW 2041 (Australia)

mjardine@georgeinstitute.org.au 
are both risk factors for the development of cardiovascular (CV) disease (CVD) [3]. Worsening CKD further increases risk of macrovascular complications, with around a 2.5-fold increase in occurrence for halving of estimated glomerular filtration rate (eGFR) [4]. Minimizing the risk of developing these significant co-morbidities is a priority in the management of T2DM. In recent years, there has been an influx of new oral glucoselowering agents, leading to multiple options for therapy, allowing for a more individualized approach.

Until recently, a standard approach to prevention of diabetes-related complications, as directed by international guidelines, has been the implementation of glucose-lowering therapy to achieve optimal glycaemia and minimization of modifiable risk factors such as hypertension. Evidence for glycaemic targets has been demonstrated in studies showing a reduction in the risk of development of microvascular complications with optimal control [5-7]. Prior to recent developments in medication for the management of T2DM, the mainstay of prevention of diabetic kidney disease has predominantly been achieved by adherence to glycaemic targets and use of renin-angiotensin system blockade in patients with microalbuminuria. However, since 2008 the American Food and Drug Agency (FDA) has mandated demonstration of $\mathrm{CV}$ safety prior to approval of new glucose-lowering agents [8]. In complying with this regulation, new trial findings have been established for both $\mathrm{CV}$ and renoprotective effects of new classes of oral glucose-lowering agents, independent of their glucose-lowering activity [9]. This has led to a paradigm shift when considering agent selection, away from traditional parameters such as $\mathrm{HbA1c}$, and towards consideration of underlying co-morbidities and personalized risk assessments. We review $\mathrm{CV}$ and kidney outcomes from the major clinical outcome trials of 3 novel classes of glucose-lowering agents, glucagon-like peptide- 1 receptor agonists (GLP-1 RAs), dipeptidyl peptidase-4 (DPP-4) inhibitors, and sodiumglucose co-transporter 2 (SGLT2) inhibitors, and provide a summary of the factors that may guide selection for individual patients.

\section{Glucagon-Like Peptide-1 Receptor Agonists}

GLP-1 RAs decrease HbA1c by stimulating glucose-dependant insulin secretion and suppressing glucagon secretion. They also delay gastric emptying, which slows glucose absorption and decreases appetite. Other metabolic effects independent of their action on the gastrointestinal tract include alterations of renal haemodynamics and renal tubular effects such as increased natriuresis, potentially leading to improved blood pressure control [10]. GLP-1 RAs have led to modest reductions in HbA1c of around $0.3-0.7 \%$ and weight loss of around 1-4 kg, making them a favourable option in overweight patients [11-17].

The CV and kidney outcomes of GLP-1 RA have been assessed in 7 major randomized controlled trials (RCTs) in 56,004 participants with T2D and either a history or risk of CVD [11-17] (shown in Table 1; Fig. 1). A recent meta-analysis of these 7 studies [18] assessed the effects of GLP-1 RAs on major adverse CV events (MACE; a composite outcome of CV death, myocardial infarction, and stroke), hospital admission for heart failure, and death from any cause in those with $(n=43,021)$ and without established CVD $(n=12,983)$. It also included 10,773 patients with an eGFR of $<60 \mathrm{~mL} / \mathrm{min}$ per $1.73 \mathrm{~m}^{2}$, providing much needed data on renoprotection. The pooled analysis demonstrated treatment with a GLP-1 RA led to a 12\% reduction in MACE (hazard ratio [HR] 0.88, 95\% CI 0.82-0.94, $p<0.0001$ ) and a number needed to treat (NNT) to prevent 1 MACE event of 75 over an estimated median follow-up of 3.2 years. The benefit for the primary MACE outcome was the same in those with and without a history of CVD at recruitment ( $p$ for interaction 0.22 ). Similarly, the benefits did not differ on the basis of baseline HbA1c (high vs. low, $p$ for interaction 0.22 ), length of trial follow-up

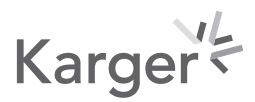


Kidney and

Blood Pressure

Research
Kidney Blood Press Res 2020;45:823-836

DOI: 10.1159/000511214

(C) 2020

www.karger.com/kb

Sukkar et al.: Review of Novel Glucose-Lowering Agents

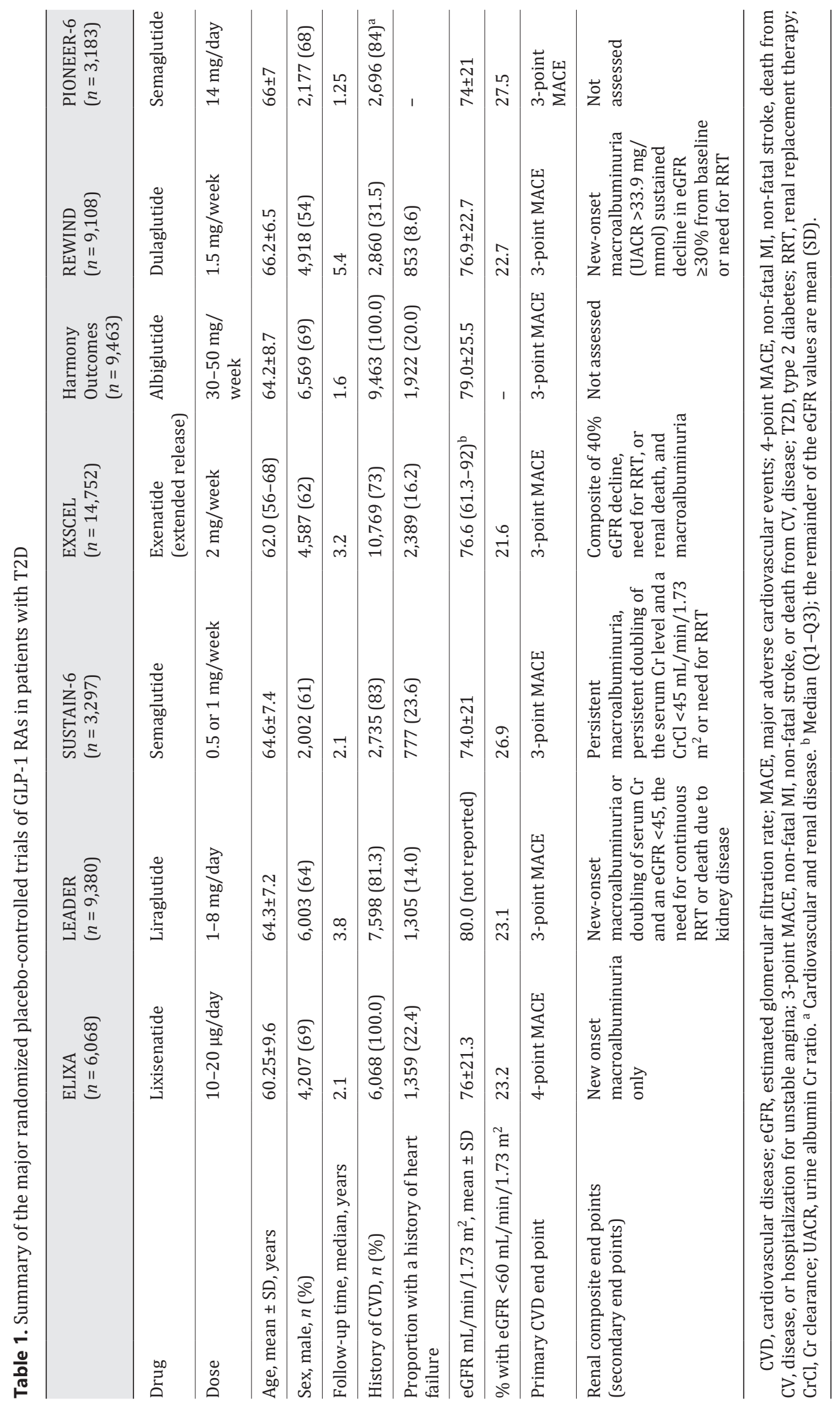


Research

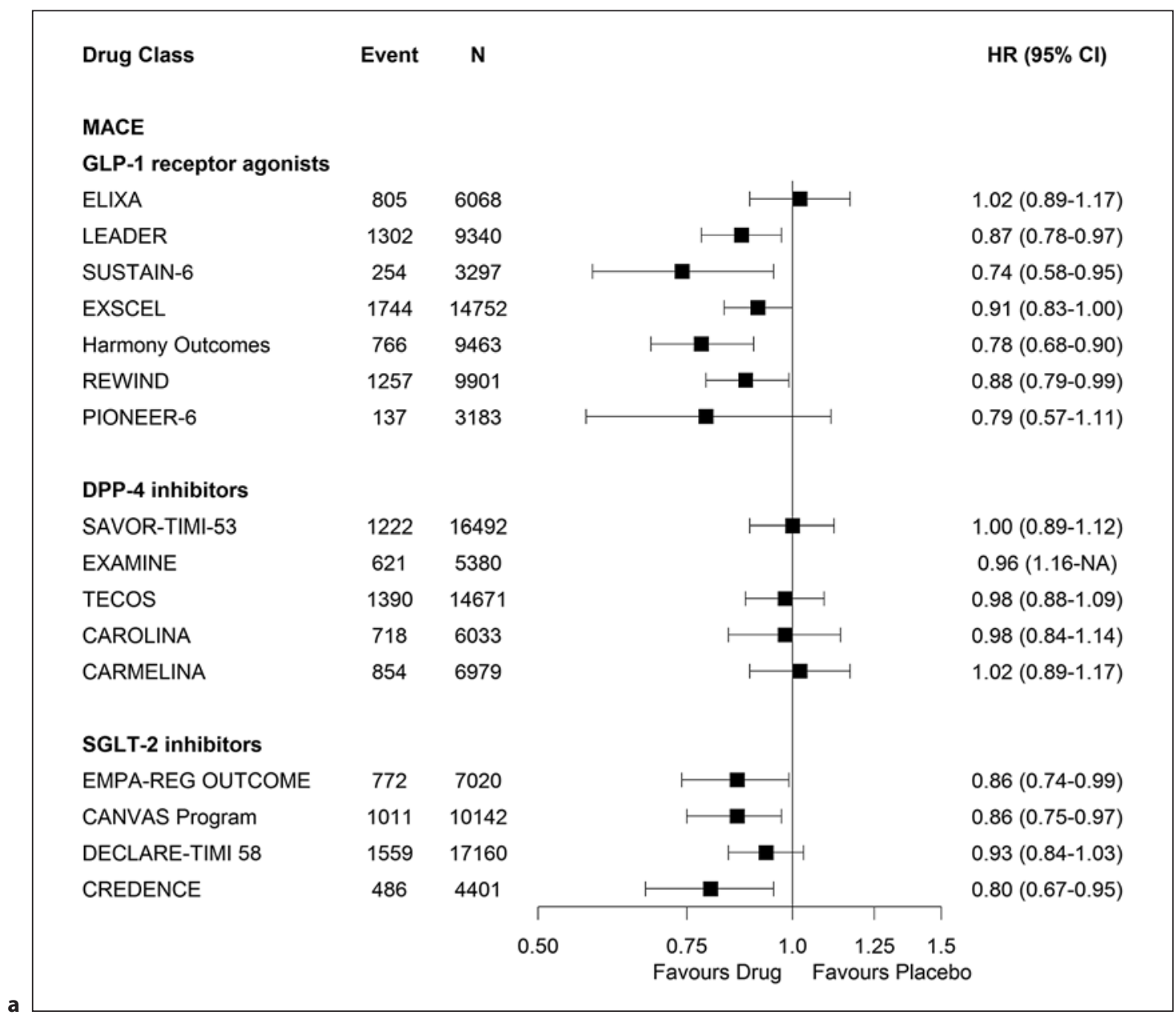

Fig. 1. A comparison of MACE (a), hospitalization for heart failure (b), and composite kidney outcomes across completed GLP-1 RAs, DPP-4 inhibitors and SGLT2 inhibitor placebo-controlled trials (c). GLP-1 RAs, glucagon-like peptide-1 receptor agonists; DPP-4, dipeptidyl peptidase-4; SGLT2, sodium-glucose co-transporter 2; MACE, major adverse cardiovascular events.

(Figure continued on next page.)

(<3 vs. $>3$ years, $p$ for interaction 0.53 ), or drug dosing interval (daily vs. weekly dosing, $p$ interaction 0.34 ).

Interestingly, heart failure hospitalizations, which were not the primary reason for any of the trials, were reduced by $9 \%$. However, as this was a pooled analysis of a secondary outcome and the effect was of borderline statistical significance (HR 0.91, 95\% CI 0.83-0.99, $p=0.028$ NNT 311), the authors were appropriately cautious in their interpretation. This intriguing finding warrants further analyses.

Kidney outcomes could be analysed in 5 major GLP-1 RA trials which included 40,302 patients [18] (shown in Table 1; Fig. 1c). The broad composite kidney outcome consisted of the development of macroalbuminuria, worsening kidney function (doubling of serum $\mathrm{Cr}$ or $40 \%$ or greater decline in eGFR), progression to end-stage kidney disease (ESKD), or death attributable to kidney causes. Treatment with a GLP-1 RA reduced the broad composite kidney outcome by $17 \%$ (HR $0.83,95 \%$ CI $0.78-0.89, p<0.0001$ ) with an NNT to prevent 1 event of 62 (48-96) over the estimated median follow-up of 3.2 years (shown in Fig. 1). However, this effect was driven mainly by a reduction in urinary albumin excretion, and the 
Kidney and

Blood Pressure

Research
Kidney Blood Press Res 2020;45:823-836

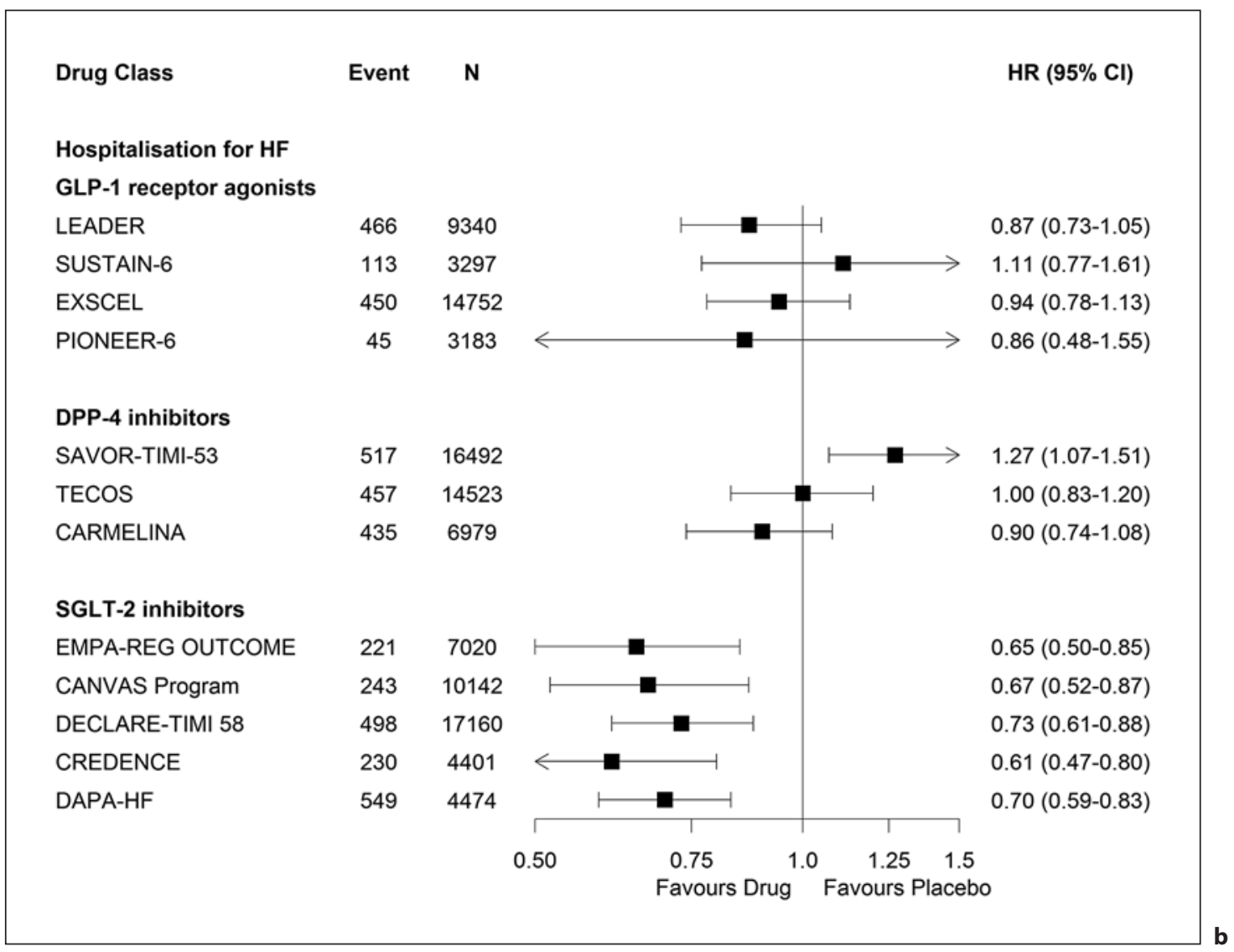

Drug Class

Event N

HR $(95 \% \mathrm{Cl})$

Composite kidney outcome GLP-1 receptor agonists

ELIXA

LEADER

SUSTAIN-6

EXSCEL

REWIND

$\begin{array}{cc}375 & 5286 \\ 605 & 9340 \\ 162 & 3297 \\ 773 & 12489 \\ 1818 & 9901\end{array}$

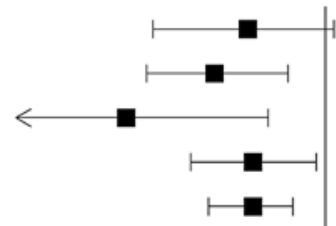

0.84 (0.68-1.02)

$0.78(0.67-0.92)$

$0.64(0.46-0.88)$

$0.85(0.74-0.98)$

$0.85(0.77-0.93)$

DPP-4 inhibitors

SAVOR-TIMI-53

372

16492

$633 \quad 6979$

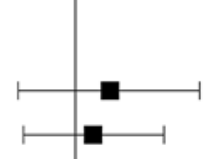

$1.08(0.88-1.32)$

$1.04(0.89-1.22)$

SGLT-2 inhibitors

EMPA-REG OUTCOME

CANVAS Program

DECLARE-TIMI

CREDENCE

DAPA-HF

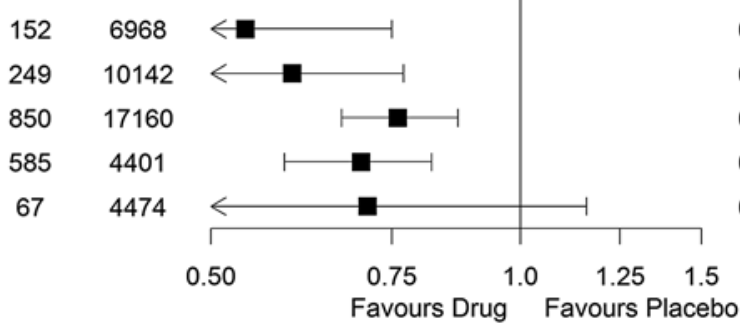

$0.54(0.40-0.75)$

$0.60(0.47-0.77)$

$0.76(0.67-0.87)$

$0.70(0.59-0.82)$

$0.71(0.44-1.16)$ 
benefit based on decline in eGFR was non-significant (HR 0.87, 95\% CI 0.73-1.03). There has not been a designated trial published to date with a primary end point of kidney outcomes, although the ongoing FLOW trial (ClinicalTrials.gov Identifier NCT03819153) in people with T2DM and an eGFR $25-50 \mathrm{~mL} / \mathrm{min} / 1.73 \mathrm{~m}^{2}$ with or without albuminuria should address whether GLP-1 RA can slow progression of CKD in T2DM.

There are notable side effects and risks with this class, with rates of permanent discontinuation due to side effects in clinical trials of around 10-15\% (11-17). The most common adverse effect was a gastrointestinal event, including nausea, vomiting, or diarrhoea. Postmarketing surveillance by the FDA has shown that this is usually transient and improves with continued use and, therefore, recommends starting at the lowest dose and slowly increasing the dose over the course of several weeks. Acute gallstone disease, including cholelithiasis and cholecystitis, has also been reported in clinical trials, and therefore, those at high risk or a previous history should be monitored closely. However, there has been no demonstrated increased risk of pancreatitis or neoplasm in any of the major trials (11-17).

In summary, GLP-1 RAs reduce the risk of all-cause mortality, myocardial infarction, and stroke, with favourable reductions in worsening kidney outcomes mainly driven by a reduction in macroalbuminuria. Further studies are needed to determine whether there is a true reduction in heart failure hospitalization. The dedicated kidney outcome FLOW trial is eagerly anticipated to assess whether GLP-1 RAs can improve outcomes based on eGFR decline.

\section{Dipeptidyl Peptidase-4 Inhibitors}

DPP-4 inhibitors increase endogenous GLP-1 activity by preventing its breakdown, resulting in a 2- to 3-fold elevation in postprandial concentrations. As a result, blood glucose levels are indirectly optimized by the prolonged GLP-1 availability. DPP-4 inhibitors are administered orally once or twice daily and are renally excreted except for linagliptin, which is excreted via the biliary route. They do not cause alterations in weight and have been shown to lower HbA1c levels by $0.5-1.0 \%$. They do not cause hypoglycaemia (20-24).

The CV and kidney outcomes of DPP-4 inhibitors have been assessed in 5 large placebocontrolled RCTs [19-23] (shown in Table 2; Fig. 1). All 5 trials demonstrated CV safety; however, DPP-4 inhibitors as a class have not shown a reduction in CV morbidity or mortality in trials that have predominantly recruited patients with a history of CVD.

Of the 5 large completed RCTs to date, the CAROLINA trial was the only one that compared a DPP-4 inhibitor against an active comparator (glimepiride) [24]. While non-inferiority for the composite CV outcome of MACE was met, superiority was not established. However, fewer symptomatic hypoglycaemic events were noted (HR 0.23, 95\% CI 0.21-0.26).

A surprising result of the DPP-4 inhibitor trials was that the effect on heart failure was not consistent among the different agents tested (shown in Fig. 1). In the SAVOUR-TIMI-53 trial, saxagliptin caused an increased risk of heart failure hospitalization in comparison with standard therapy (HR 1.27, 95\% CI 1.07-1.51) [20] but not for the other DPP-4 inhibitors. A post hoc analysis of the SAVOUR-TIMI-53 trial illustrated the excess risk was predominantly in the first 12 months of initiation of therapy and was predominantly in people with previous history of heart failure, those with impaired renal function, and those with an elevated $\mathrm{N}$-terminal pro-B-type natriuretic peptide [25]. The FDA subsequently issued a warning that saxagliptin should be avoided in patients with a history of heart failure.

The major trials examining kidney outcomes in DPP-4 inhibitors have demonstrated limited benefit with modest improvements in albuminuria and no benefits seen in change in eGFR or risk of ESKD. Of note, the CARMELINA trial which enrolled participants with both

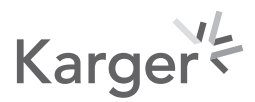




\section{Research}

\begin{tabular}{l|l}
\hline DOI: 10.1159/000511214 & $\begin{array}{l}\text { C } 2020 \text { The Author(s). Published by S. Karger AG, Basel } \\
\text { www.karger.com/kbr }\end{array}$
\end{tabular}

Sukkar et al.: Review of Novel Glucose-Lowering Agents

Table 2. Summary of completed placebo-controlled DPP-4 inhibitor outcome trials in patients with T2D

\begin{tabular}{|c|c|c|c|c|c|}
\hline & $\begin{array}{l}\text { SAVOR-TIMI-53 } \\
(n=16,492)\end{array}$ & $\begin{array}{l}\text { EXAMINE } \\
(n=5,380)\end{array}$ & $\begin{array}{l}\text { TECOS } \\
(n=14,671)\end{array}$ & $\begin{array}{l}\text { CAROLINA } \\
(n=6,042)\end{array}$ & $\begin{array}{l}\text { CARMELINA } \\
(n=6,979)\end{array}$ \\
\hline Drug & Saxagliptin & Alogliptin & Sitagliptin & Linagliptin & Linagliptin \\
\hline Dose & $2.5-5 \mathrm{mg}$ daily & $6.25-25 \mathrm{mg}$ daily & $\begin{array}{l}\text { 50-100 mg } \\
\text { daily }\end{array}$ & $\begin{array}{l}5 \text { mg daily } \\
\text { versus } \\
\text { glimepiride } \\
1-4 \text { mg daily }\end{array}$ & 5 mg daily \\
\hline Age, mean $\pm S D$, years & $65 \pm 8.5$ & $61^{\mathrm{a}}$ & $65.5 \pm 8.0$ & $64.0 \pm 9.5$ & $65.8 \pm 9.1$ \\
\hline Sex, male, $n(\%)$ & $11,037(67.0)$ & $3,647(67.8)$ & $10,374(78.7)$ & $3,625(60.0)$ & $4,390(63.0)$ \\
\hline Median follow-up (IQR), years & $2.1(1.8-2.3)$ & $1.4(0.8-2.0)$ & $3.0(2.3-3.8)$ & $6.3(5.9-6.6)$ & $\begin{array}{l}2.2 \text { (not } \\
\text { reported) }\end{array}$ \\
\hline History of CVD, $n(\%)$ & $12,946(78.5)$ & $4,732(88.0)$ & $10,863(74.0)$ & $2,522(41.7)$ & $3,978(57)$ \\
\hline $\begin{array}{l}\text { Proportion with a history of heart } \\
\text { failure }\end{array}$ & $2,111(12.8)$ & $1,501(27.9)$ & $2,643(18.0)$ & $271(4.5)$ & $1,873(26.8)$ \\
\hline Mean eGFR $( \pm$ SD $)$ & $72.5( \pm 22.6)$ & $\begin{array}{l}71.2 \text { (not } \\
\text { provided) }\end{array}$ & $74.9( \pm 21.1)$ & $76.5( \pm 19.7)$ & $54.6( \pm 25)$ \\
\hline$\%$ with eGFR $<60 \mathrm{~mL} / \mathrm{min} / 1.73 \mathrm{~m}^{2}$ & $15.6^{\mathrm{a}}$ & 29.1 & $9.4^{\mathrm{a}}$ & 18.7 & 19.3 \\
\hline Primary CVD end point & 3-point MACE & 3-point MACE & $\begin{array}{l}\text { 3-point } \\
\text { MACE }\end{array}$ & 3-point MACE & 3-point MACE \\
\hline Renal composite end points & $\begin{array}{l}\text { Composite of doubling } \\
\text { of serum } \mathrm{Cr} \text {, initiation } \\
\text { of RRT or } \\
\text { transplantation or } \mathrm{Cr} \\
>6.0 \mathrm{mg} / \mathrm{dL}(530 \\
\mu \mathrm{mol} / \mathrm{L})\end{array}$ & $\begin{array}{l}\text { Mean change in } \\
\text { eGFR according } \\
\text { to baseline } \\
\text { kidney function }{ }^{b}\end{array}$ & $\begin{array}{l}\text { Mean change } \\
\text { from baseline } \\
\text { eGFR }\end{array}$ & Not assessed & $\begin{array}{l}\text { Time to } \\
\text { composite of } \\
\text { ESRD, death due } \\
\text { to renal failure, } \\
\text { sustained } \\
\text { decrease in eGFR } \\
\geq 40 \%\end{array}$ \\
\hline
\end{tabular}

SD, standard deviation; IQR, interquartile range; CVD, cardiovascular disease; eGFR, estimated glomerular filtration rate; MACE, major adverse cardiovascular events; 3-point MACE, non-fatal MI, non-fatal stroke, death from CVD, disease, or hospitalization; RRT, renal replacement therapy; T2D, type 2 diabetes. ${ }^{a}$ Percentage with eGFR $\leq 50 \mathrm{~mL} / \mathrm{min} / 1.73 \mathrm{~m}^{2} .{ }^{\mathrm{b}}$ Mean change in eGFR, for alogliptin versus placebo did not provide a test of statistical comparison.

high CV risk and renal risk (reduced eGFR and microalbuminuria or macroalbuminuria) found no difference in rates of the composite kidney outcomes of $\geq 40 \%$ reduction in eGFR, ESKD, or death from kidney failure (HR 1.04, 95\% CI 0.89-1.22). This was despite a reduction in progression of albuminuria (HR 0.86, 95\% CI 0.78-0.95) [23]. These findings have been supported by a meta-analysis (excluding CARMELINA) which concluded that there was no impact on the risk of kidney failure (HR 1.06, 95\% CI 0.88-1.27) [26].

As a class, DPP-4 inhibitors have shown good safety and tolerability profiles with no difference in the incidence of serious adverse events compared to placebo in the major RCTs. In post-marketing surveillance reported by the FDA, however, several adverse events have been recorded including an increased incidence of pancreatitis, severe and disabling arthralgias, and bullous pemphigoid requiring hospitalization. While rare events, patients on these medications should be advised to report any joint or skin changes to their treating physician for assessment and referral as appropriate. 
In summary, DPP-4 inhibitors have demonstrated CV safety but no CV or kidney benefit in people with established CVD. They have a low side-effect profile and good tolerability, making them particularly suited to the frail elderly.

\section{SGLT2 Inhibitors}

SGLT2 inhibitors block SGLT2 co-transporters on the luminal surface of the proximal renal tubule. The resultant increase in glucosuria and natriuresis contributes to a broad range of metabolic benefits, including reductions in glycosylated haemoglobin of around a $0.5-0.7 \%$, body weight of around 2-3 kg, and improvements in blood pressure [27-29].

The data for beneficial CV outcomes are robust. To date, there have been 5 major completed RCTs reporting the effects of SGLT2 inhibitors in people with T2DM, and 1 trial in people with heart failure and reduced ejection fraction both with and without diabetes [2934] (shown in Table 3; Fig. 1). The reported studies collectively enrolled over 48,000 participants with and without established atherosclerotic CVD (ASCVD). CREDENCE enrolled over 4,000 participants and was specifically designed to assess the effects of canagliflozin primarily on kidney outcomes in patients with albuminuric CKD [32]. Patients across all major trials were largely receiving cardioprotective treatment, with at least $80 \%$ of participants on reninangiotensin system blockade, including all participants in CREDENCE by design, and around $60-70 \%$ on lipid-lowering therapy. The cardioprotective benefits in all these major trials appear consistent, with a recent meta-analysis (not including the recently completed VERTIS CV trial) [34] demonstrating overall benefit for MACE (a composite outcome of CV death, myocardial infarction, and stroke) (HR 0.88, 95\% CI 0.82-0.94, $p<0.001$ ) in patients randomized to receive an SGLT2 inhibitor. These cardioprotective benefits were observed irrespective of baseline history of ASCVD ( $p$ for interaction 0.25) or heart failure ( $p$ for interaction 0.59). Similarly, the benefits did not differ across a range of baseline kidney function from $30 \mathrm{~mL} / \mathrm{min} / 1.73 \mathrm{~m}^{2}$ and higher [35].

Similarly, a pooled analysis demonstrated SGLT2 inhibitors reduced the risk of hospitalization for heart failure by $32 \%$ (HR $0.68,95 \%$ CI $0.60-0.76$ ) with no evidence of heterogeneity between studies $\left(I^{2}=0 ; p\right.$ for interaction 0.72$)$. This was irrespective of history of ASCVD ( $p$ for interaction 0.49), presence or absence of baseline heart failure ( $p$ for interaction 0.82 ), or CKD (defined as eGFR $<60 \mathrm{~mL} / \mathrm{min} / 1.73 \mathrm{~m}^{2}$ ) ( $p$ for interaction 0.30 ) [35]. The renoprotective effects demonstrated in major RCTs of SGLT2 inhibitors offer a promising new evidence-based approach for the prevention of diabetic kidney disease. The CREDENCE trial designed specifically to address outcomes in people with T2DM, an eGFR $<60 \mathrm{~mL} / \mathrm{min} / 1.73$ $\mathrm{m}^{2}$, and macroalbuminuria was ceased early after an interim analysis demonstrated efficacy for the primary outcome of composite of ESKD (dialysis, transplantation, or a sustained estimated GFR of $<15 \mathrm{~mL} / \mathrm{min} / 1.73 \mathrm{~m}^{2}$ ), a doubling of the serum $\mathrm{Cr}$ level, or death from renal or $\mathrm{CV}$ causes. The relative risk of the primary outcome was $30 \%$ lower in the canagliflozin group than in the placebo group (HR 0.70, 95\% CI 0.59-0.82) [32] (shown in Fig. 1). Secondary analysis demonstrated consistent results across eGFR subgroups, including among those initiating treatment with eGFR as low as $30 \mathrm{~mL} / \mathrm{min} / 1.73 \mathrm{~m}^{2}[36]$. In a recent meta-analysis of major trials, SGLT2 inhibitors considerably reduced the risk of dialysis, transplantation, or death due to kidney disease by $33 \%$ (RR $0.67,95 \%$ CI $0.52-0.86, p=0.0019$ ) as well as reduced the risk of ESKD by 35\% (HR $065,95 \%$ CI $0.53-0.81, p<0.005$ ), an effect that appeared consistent across studies [37].

The recently completed VERTIS-CV trial of ertugliflozin [34] did not show overall benefit for MACE (HR 0.97, 95\% CI 0.85-1.11, $p<0.001$ ) nor the composite renal outcome (doubling of serum Cr, need for RRT/transplantation, or death due to renal causes) (HR 0.81 95\% CI 
Kidney and

Blood Pressure

Research
Kidney Blood Press Res 2020;45:823-836

DOI: $10.1159 / 000511214$

www.karger.com/kb

Sukkar et al.: Review of Novel Glucose-Lowering Agents

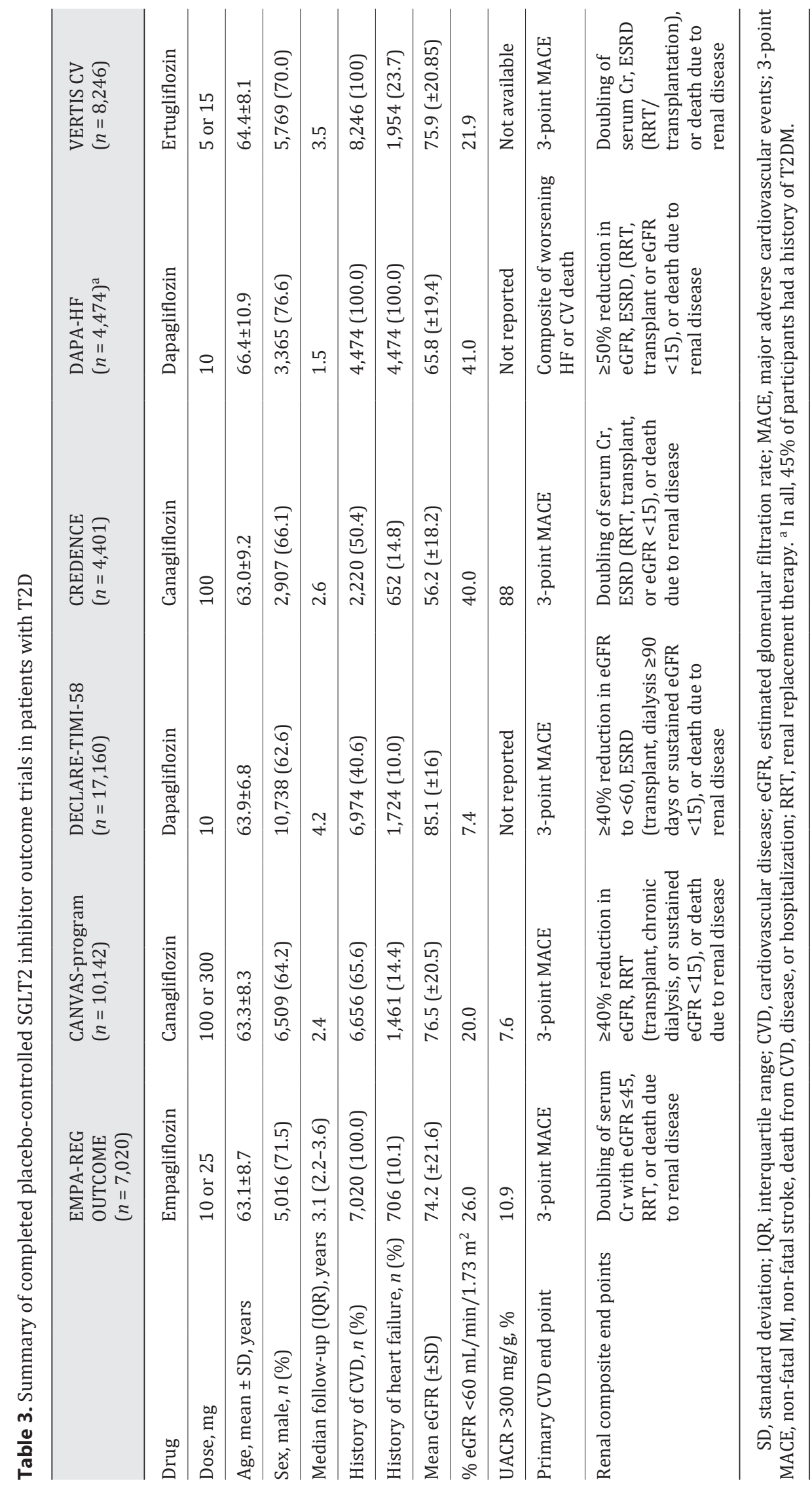


Table 4. Metabolic effects, safety, and prescribing considerations for GLP-1 RAs, DPP-4 inhibitors, and SGLT2 inhibitors

\begin{tabular}{|c|c|c|c|}
\hline & GLP-1 RA & DPP-4 inhibitors & SGLT2 inhibitors \\
\hline Average $\mathrm{HbA} 1 \mathrm{c}$ reduction & $0.3-0.7 \%$ & $0.5-1.0 \%$ reduction & $0.3-0.6 \%$ reduction \\
\hline Weight & 1-4 kg weight loss & No weight loss or gain & $0.8-2.0 \mathrm{~kg}$ weight loss \\
\hline $\begin{array}{l}\text { Blood pressure decrease (systolic/ } \\
\text { diastolic) }\end{array}$ & $1-5 / 4-5 \mathrm{~mm} \mathrm{Hg}$ & No difference observed ${ }^{a}$ & $3-4 / 1-2 \mathrm{~mm} \mathrm{Hg}$ \\
\hline Method of administration & $\begin{array}{l}\text { Injectable (except } \\
\text { semaglutide, which is } \\
\text { oral) }\end{array}$ & Oral & Oral \\
\hline Main adverse events & $\begin{array}{l}\text { GI: nausea, vomiting, } \\
\text { diarrhoea, cholelithiasis, } \\
\text { and cholecystitis }\end{array}$ & Well tolerated & $\begin{array}{l}\text { Genital fungal infections, } \\
\text { euglycaemic DKA, and volume } \\
\text { depletion }\end{array}$ \\
\hline Prescribing considerations & $\begin{array}{l}\text { Cannot be used } \\
\text { concurrently with DPP-4 } \\
\text { inhibitors }\end{array}$ & $\begin{array}{l}\text { Dose reduction } \\
\text { recommended when used } \\
\text { with CYP3A/4/5 } \\
\text { inhibitors }^{\text {b }}\end{array}$ & $\begin{array}{l}\text { A reversible decrease in eGFR of } \\
<30 \% \text { may occur and is generally } \\
\text { not an indication to discontinue } \\
\text { therapy }\end{array}$ \\
\hline
\end{tabular}

HbA1c, glycated haemoglobin; CYP3A/4/5, cytochrome P450 isoform 3 A, isoform 4, and isoform 5 inhibitors. ${ }^{\text {a }}$ Only reported in CARMELINA [22]. ${ }^{\mathrm{b}}$ For example, antifungals, anti-retrovirals, macrolide antibiotics.

$0.63-1.04, p 0.08$ ) but did show benefit for reduction in heart failure hospitalization (HR 0.70, $95 \%$ CI $0.54-0.90, p<0.0001$ ) consistent with the class effect. At this stage, it is unclear whether the lack of an effect seen on MACE and renal outcomes is a result of differences in the population studied, a biological difference in the drug itself, the implementation of the trial, or differences in adherence. Further analyses from the trial may reveal future insights.

Along with the published results of the VERTIS-CV trial, further results on renal outcomes are expected. The DAPA-CKD trial (ClinicalTrials.gov Identifier NCT03036150) (dapagliflozin, $n \approx 4,300$ ) will evaluate the effect of dapagliflozin on renal outcomes and CV mortality in people with CKD both with and without T2DM. This trial was ceased early in March 2020 after pre-specified efficacy criteria were met with results expected later in the year. In addition, the Study of Heart and Kidney Protection with Empagliflozin (EMPA-KIDNEY ClinicalTrials. gov Identifier NCT03594110) [38] is also underway and aims to investigate the effects of SGLT2 inhibitors on CKD progression and CV mortality independent of diabetes status and presence of albuminuria. The results of these trials will help determine whether this class of medication can safely be used down to an eGFR of $20-25 \mathrm{~mL} / \mathrm{min} / 1.73 \mathrm{~m}^{2}$ and importantly provide evidence on the efficacy of these medications in non-diabetic kidney disease.

There are well-described risks of adverse effects associated with SGLT2 inhibitors (shown in Table 4). One of the most commonly reported adverse effects are genital fungal infections with a meta-analysis of 86 trials reporting a 3-fold increased risk (RR 3.37, 95\% CI 2.89-3.93) in SGLT2 inhibitors compared to placebo [39]. Maintaining good genital hygiene can reduce this risk. The risk of bacterial urinary tract infections appears less significant [40]. Euglycaemic diabetic ketoacidosis is a rare but serious adverse event that occurred in $0.1 \%$ in RCT cohorts. Observational data suggest this is most likely to affect patients on insufficient insulin, reduced carbohydrate intake, volume depletion, and concomitant infection [41]. Educating patients about DKA signs and symptoms, sick day care, and the importance of seeking prompt medical attention may help mitigate this risk [42]. Initial safety concerns of an increased fracture risk with canagliflozin from the CANVAS trial have been resolved in subsequent secondary analyses $[43,44]$ and were not observed in the CREDENCE trial [32]. 
Table 5. Prescribing considerations across the eGFR ranges tested in the large RCTs

\begin{tabular}{|c|c|c|c|c|}
\hline \multirow[t]{2}{*}{ Drug class } & \multicolumn{4}{|l|}{ eGFR } \\
\hline & $\begin{array}{l}\mathrm{eGFR}>60 \mathrm{~mL} / \\
\mathrm{min} / 1.73 \mathrm{~m}^{2}\end{array}$ & $\begin{array}{l}\text { eGFR } 45-59 \\
\mathrm{~mL} / \mathrm{min} / 1.73 \\
\mathrm{~m}^{2}\end{array}$ & eGFR $30-44 \mathrm{~mL} / \mathrm{min} / 1.73 \mathrm{~m}^{2}$ & eGFR $15-29 \mathrm{~mL} / \mathrm{min} / 1.73 \mathrm{~m}^{2}$ \\
\hline GLP-1 RAs & No adjustment & No adjustment & No adjustment & $\begin{array}{l}\text { Efficacy and safety assessed in } \\
\text { dulaglutide }(47)^{\mathrm{a}}\end{array}$ \\
\hline $\begin{array}{l}\text { DPP-4 } \\
\text { inhibitors }\end{array}$ & No adjustment & No adjustment & $\begin{array}{l}\text { Saxagliptin dose reduced to } 2.5 \mathrm{mg} \text { daily } \\
\text { Sitagliptin/vilagliptin dose reduced to } \\
50 \mathrm{mg} \text { daily } \\
\text { Alogliptin reduced to } 12.5 \mathrm{mg} \text { daily }\end{array}$ & $\begin{array}{l}\text { Saxagliptin dose reduced to } 2.5 \mathrm{mg} \\
\text { daily } \\
\text { Sitagliptin dose reduced to } 25 \mathrm{mg} \\
\text { daily } \\
\text { Vildagliptin reduced to } 50 \mathrm{mg} \text { daily } \\
\text { Alogliptin reduced to } 6.25 \mathrm{mg} \text { daily }\end{array}$ \\
\hline $\begin{array}{l}\text { SGLT2 } \\
\text { inhibitors }\end{array}$ & No adjustment & No adjustment & $\begin{array}{l}\text { Not licensed eGFR }<45 \mathrm{~mL} / \mathrm{min} / 1.73 \mathrm{~m}^{2 \mathrm{a}} \text {, } \\
\text { although allowable in some guidelines to } \\
\text { eGFR }<30 \mathrm{~mL} / \mathrm{min}^{\mathrm{b}}\end{array}$ & $\begin{array}{l}\text { No RCT evidence in people starting } \\
\text { with an eGFR }<30 \mathrm{~mL} / \mathrm{min} / 1.73 \mathrm{~m}^{2} \\
\text { Trials to eGFR } 20 \mathrm{~mL} / \mathrm{min} \\
\text { underway }\end{array}$ \\
\hline
\end{tabular}

eGFR, estimated glomerular filtration rate; RCT, randomized controlled trials; SGLT2, sodium-glucose co-transporter 2; DPP, dipeptidyl peptidase; GLP-1 RAs, glucagon-like peptide-1 receptor agonists. ${ }^{a}$ As demonstrated in the AWARD-7 trial. ${ }^{b}$ Based on the results of the CREDENCE trial.

Data regarding amputation risk are more heterogeneous, with an overall increased risk seen in a recent secondary analysis of the CANVAS programme (HR 1.97, 95\% CI 1.41-2.75) and the CREDENCE trial (HR 1.11, 95\% CI 0.79-1.55), but with significant trial heterogeneity ( $p$ heterogeneity of 0.02 and an $I^{2}$ of $82 \%$ ) [45].

In summary, SGLT2 inhibitors offer CV and renoprotective benefits especially in people with established ASCVD and albuminuric CKD. However, it remains unclear whether these benefits can be extended to people with advanced CKD and those with non-diabetic kidney disease. Findings from DAPA-CKD and EMPA-KIDNEY are eagerly awaited to help fill these knowledge gaps.

\section{An Update on Changes in Society Guideline Recommendations}

The evidence for CV and kidney benefits provided by the recently completed RCTs in the 3 classes of glucose-lowering agents discussed above have allowed for a more individualized approach to the management of patients with T2DM. The choice of glucose-lowering agent can now be made based on underlying CV and risk of kidney disease progression instead of glycaemic parameters, representing a key paradigm shift in the management of people with diabetes.

As a result, several international clinical practice guidelines have been updated or are in the process of being updated to reflect the evolving and emerging evidence for CV and kidney protection. Major updates include a joint position statement from the European Association for the Study of Diabetes (EASD) and the American Diabetes Association (ADA), the ADA Standards of Care [46, 47], and the Kidney Disease Improving Global Outcomes (KDIGO) practice guideline on diabetes management in CKD (currently under public review and due to be published in September 2020). While all guidelines maintain their recommendation for metformin as the preferred first-line agent in diabetes management after lifestyle changes, the decision to commence a second-line agent is now based on end-organ protection and patient co-morbidities. In regard to CV disease prevention, most guidelines recommend either GLP-1 
RAs or a SGLT2 inhibitor as second-line treatment (after metformin) in people with a history of ASCV (secondary prevention) or at high risk of CV disease (primary prevention).

Given the consistent evidence that SGLT2 inhibitors reduce the risk of hospitalization for heart failure and kidney disease progression (shown in Fig. 1), the ADA-EASD consensus report recommends the use of SGLT2 inhibitors in people with heart failure or CKD (irrespective of history of ASCD). Based on the results of the CREDENCE trial, the updated 2019 ADA Standards of Care specifically endorse the use of SGLT2 inhibitors for the prevention of kidney failure, CV events, or both in patients with an eGFR $>30 \mathrm{~mL} / \mathrm{min} / 1.73 \mathrm{~m}^{2}$, particularly in those with severely increased albuminuria. However, GLP-1 RA should be prioritized in patients with eGFR $<30 \mathrm{~mL} /$ $\mathrm{min} / 1.73 \mathrm{~m}^{2}$ (shown in Table 5). This may change once the results of the SGLT2 inhibitor trials DAPA-CKD and EMPA-KIDNEY become available in the next 6-12 months.

DPP-4 inhibitors do not offer any CV or renal protection to patients with T2DM. The guidelines thus suggest these agents as add-on therapy to metformin for inadequate glycaemia management in those with strong contraindications to SGLT2 inhibitors and GLP-1 RAs or when SGLT2 inhibitors and GLP-1 RAs are not tolerated.

\section{Conclusion}

We have outlined 3 novel classes of glucose-lowering agents that may help clinicians tailor individual regimens to patient risk profiles and goals with their diabetes management. With careful consideration regarding possible $\mathrm{CV}$ and kidney protection, and patient education regarding potential adverse effects, they all offer useful options for diabetes management that may reduce risk of disease complications. Current studies and ongoing real-world data collection will help further optimize patient selection for each class.

\section{Acknowledgement}

We would like to acknowledge Dr. Carinna Hockham who drafted the forest plots included in this article.

\section{Conflict of Interest Statement}

L.S. and T.Y. have no conflicts of interest to disclose. M.J. is responsible for research programmes that have received unrestricted funding from Gambro, Baxter, Commonwealth Serum Laboratories (CSL), Amgen, Eli Lilly, and Merck; has served on advisory boards and steering committees sponsored by Akebia, Baxter, Boehringer Ingelheim, CSL, Janssen, and Vifor; and spoken at scientific meetings sponsored by Janssen, Amgen, and Roche, with any consultancy, honoraria, or travel support paid to her institution.

\section{Funding Sources}

There was no specific funding received for this narrative review. L.S. is supported by the George Institute Postgraduate Scholarship from the George Institute for Global Health and an Australian Postgraduate Award from the University of Sydney, T.Y. is supported by a University Postgraduate Award from the University of NSW, and M.J. is supported by a Medical Research Future Fund Generation Clinical Researchers Program Career Development Fellowship.

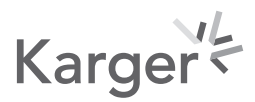




\section{Author Contributions}

L.S., T.Y., and M.J. were responsible for narrative review concept. L.S. and T.Y. are equal first authors and drafted the manuscript. All authors gave critical revision of the manuscript for important intellectual content and interpreted all studies included within.

\section{References}

1 Cho NH, Shaw JE, Karuranga S, Huang Y, da Rocha Fernandes JD, Ohlrogge AW, et al. IDF diabetes atlas: global estimates of diabetes prevalence for 2017 and projections for 2045. Diabetes Res Clin Pract. 2018 Apr;138: 271-81.

2 Hill NR, Fatoba ST, Oke JL, Hirst JA, O'Callaghan CA, Lasserson DS, et al. Global prevalence of chronic kidney disease: a systematic review and meta-analysis. PLoS One. 2016;11(7):e0158765.

3 Tonelli M, Muntner P, Lloyd A, Manns BJ, Klarenbach S, Pannu N, et al. Risk of coronary events in people with chronic kidney disease compared with those with diabetes: a population-level cohort study. Lancet. 2012 Sep 1;380(9844):807-14.

4 Ninomiya T, Perkovic V, de Galan BE, Zoungas S, Pillai A, Jardine M, et al. Albuminuria and kidney function independently predict cardiovascular and renal outcomes in diabetes. J Am Soc Nephrol. 2009 Aug;20(8): 1813-21.

5 Nathan DM, Nathan DM, Genuth S, Lachin J, Cleary P, Crofford O, et al. The effect of intensive treatment of diabetes on the development and progression of long-term complications in insulin-dependent diabetes mellitus. N Engl J Med. 1993 Sep 30;329(14):977-86.

6 Intensive blood-glucose control with sulphonylureas or insulin compared with conventional treatment and risk of complications in patients with type 2 diabetes (UKPDS 33). UK Prospective Diabetes Study (UKPDS) Group. Lancet. 1998 Sep 12;352(9131):837-53.

7 Turner RC, Cull CA, Frighi V, Holman RR. Glycemic control with diet, sulfonylurea, metformin, or insulin in patients with type 2 diabetes mellitus: progressive requirement for multiple therapies (UKPDS 49). UK Prospective Diabetes Study (UKPDS) Group. JAMA. 1999 Jun 2;281(21):2005-12.

8 Wang CCL, Everett BM, Burman KD, Wilson PWF. Cardiovascular safety trials for all new diabetes mellitus drugs? Circulation. 2019;139(14):1741-43.

9 Cefalu WT, Kaul S, Gerstein HC, Holman RR, Zinman B, Skyler JS, et al. Cardiovascular outcomes trials in type 2 diabetes: where do we go from here? reflections from a diabetes care editors' expert forum. Diabetes Care. 2018;41(1):14-31.

10 Muskiet MHA, Tonneijck L, Smits MM, van Baar MJB, Kramer MHH, Hoorn EJ, et al. GLP-1 and the kidney: from physiology to pharmacology and outcomes in diabetes. Nat Rev Nephrol. 2017 Oct;13(10):605-28.

11 Pfeffer MA, Claggett B, Diaz R, Dickstein K, Gerstein HC, Køber LV, et al. Lixisenatide in patients with type 2 diabetes and acute coronary syndrome. N Engl J Med. 2015 Dec 3;373(23):2247-57.

12 Marso SP, Bain SC, Consoli A, Eliaschewitz FG, Jódar E, Leiter LA, et al. Semaglutide and cardiovascular outcomes in patients with type 2 diabetes. N Engl J Med. 2016;375(19):1834-44.

13 Marso SP, Daniels GH, Brown-Frandsen K, Kristensen P, Mann JF, Nauck MA, et al. Liraglutide and cardiovascular outcomes in type 2 diabetes. N Engl J Med. 2016 Jul 28;375(4):311-22.

14 Holman RR, Bethel MA, Mentz RJ, Thompson VP, Lokhnygina Y, Buse JB, et al. Effects of once-weekly exenatide on cardiovascular outcomes in type 2 diabetes. N Engl J Med. 2017;377(13):1228-39.

15 Hernandez AF, Green JB, Janmohamed S, D’Agostino Sr RB, Granger CB, Jones NP, et al. Albiglutide and cardiovascular outcomes in patients with type 2 diabetes and cardiovascular disease (Harmony Outcomes): a double-blind, randomised placebo-controlled trial. Lancet. 2018 Oct 27;392(10157):1519-29.

16 Gerstein HC, Colhoun HM, Dagenais GR, Diaz R, Lakshmanan M, Pais P, et al. Dulaglutide and cardiovascular outcomes in type 2 diabetes (REWIND): a double-blind, randomised placebo-controlled trial. Lancet. 2019 Jul 13;394(10193):121-30.

17 Husain M, Birkenfeld AL, Donsmark M, Dungan K, Eliaschewitz FG, Franco DR, et al. Oral semaglutide and cardiovascular outcomes in patients with type 2 diabetes. N Engl J Med. 2019 Aug 29;381(9):841-51.

18 Kristensen SL, Rørth R, Jhund PS, Docherty KF, Sattar N, Preiss D, et al. Cardiovascular, mortality, and kidney outcomes with GLP-1 receptor agonists in patients with type 2 diabetes: a systematic review and metaanalysis of cardiovascular outcome trials. Lancet Diabetes Endocrinol. 2019 Oct;7(10):776-85.

19 Scirica BM, Bhatt DL, Braunwald E, Steg PG, Davidson J, Hirshberg B, et al. Saxagliptin and cardiovascular outcomes in patients with type 2 diabetes mellitus. N Engl J Med. 2013;369(14):1317-26.

20 Scirica BM, Bhatt DL, Braunwald E, Steg PG, Davidson J, Hirshberg B, et al. Saxagliptin and cardiovascular outcomes in patients with type 2 diabetes mellitus. N Engl J Med. 2013 Oct 3;369(14):1317-26.

21 White WB, Cannon CP, Heller SR, Nissen SE, Bergenstal RM, Bakris GL, et al. Alogliptin after acute coronary syndrome in patients with type 2 diabetes. N Engl J Med. 2013;369(14):1327-35.

22 Green JB, Bethel MA, Armstrong PW, Buse JB, Engel SS, Garg J, et al. Effect of sitagliptin on cardiovascular outcomes in type 2 diabetes. N Engl J Med. 2015;373(3):232-42. 
23 Rosenstock J, Perkovic V, Johansen OE, Cooper ME, Kahn SE, Marx N, et al. Effect of linagliptin vs placebo on major cardiovascular events in adults with type 2 diabetes and high cardiovascular and renal risk: the CARMELINA randomized clinical trial. JAMA. 2019;321(1):69-79.

24 Rosenstock J, Kahn SE, Johansen OE, Zinman B, Espeland MA, Woerle HJ, et al. Effect of linagliptin vs glimepiride on major adverse cardiovascular outcomes in patients with type 2 diabetes: the CAROLINA randomized clinical trial. JAMA. 2019 Sep 19;322(12):1155-66.

25 Scirica BM, Braunwald E, Raz I, Cavender MA, Morrow DA, Jarolim P, et al. Heart failure, saxagliptin, and diabetes mellitus: observations from the SAVOR-TIMI 53 randomized trial. Circulation. 2015 Oct 13;132(15): e198.

26 Rehman MB, Tudrej BV, Soustre J, Buisson M, Archambault P, Pouchain D, et al. Efficacy and safety of DPP-4 inhibitors in patients with type 2 diabetes: meta-analysis of placebo-controlled randomized clinical trials. Diabetes Metab. 2017 Feb;43(1):48-58.

27 Cefalu WT, Leiter LA, de Bruin TW, Gause-Nilsson I, Sugg J, Parikh SJ. Dapagliflozin's effects on glycemia and cardiovascular risk factors in high-risk patients with type 2 diabetes: a 24 -week, multicenter, randomized, double-blind, placebo-controlled study with a 28-week extension. Diabetes Care. 2015;38(7):1218-27.

28 Cefalu WT, Stenlöf K, Leiter LA, Wilding JP, Blonde L, Polidori D, et al. Effects of canagliflozin on body weight and relationship to HbA1c and blood pressure changes in patients with type 2 diabetes. Diabetologia. 2015; 58(6):1183-7.

29 Zinman B, Wanner C, Lachin JM, Fitchett D, Bluhmki E, Hantel S, et al. Empagliflozin, cardiovascular outcomes, and mortality in type 2 diabetes. N Engl J Med. 2015;373(22):2117-28.

30 Neal B, Perkovic V, Mahaffey KW, de Zeeuw D, Fulcher G, Erondu N, et al. Canagliflozin and cardiovascular and renal events in type 2 diabetes. N Engl J Med. 2017;377(7):644-57.

31 McMurray JJV, Solomon SD, Inzucchi SE, Køber L, Kosiborod MN, Martinez FA, et al. Dapagliflozin in patients with heart failure and reduced ejection fraction. N Engl J Med. 2019 Nov 21;381(21):1995-2008.

32 Perkovic V, Jardine MJ, Neal B, Bompoint S, Heerspink HJL, Charytan DM, et al. Canagliflozin and renal outcomes in type 2 diabetes and nephropathy. N Engl J Med. 2019;380(24):2295-306.

33 Wiviott SD, Raz I, Bonaca MP, Mosenzon 0, Kato ET, Cahn A, et al. Dapagliflozin and cardiovascular outcomes in type 2 diabetes. N Engl J Med. 2019 Jan 24;380(4):347-57.

34 Cannon CP, McGuire DK, Cherney D. Results of the eValuation of ERTugliflozin EffIcacy and Safety CardioVascular Outcomes Trial (VERTIS CV). Presented at: 80th American Diabetes Association Scientific Sessions; 2020.

35 Arnott C, Li Q, Kang A, Neuen BL, Bompoint S, Lam CSP, et al. Sodium-glucose cotransporter 2 inhibition for the prevention of cardiovascular events in patients with type 2 diabetes mellitus: a systematic review and meta-analysis. J Am Heart Assoc. 2020 Feb 4;9(3):e014908.

36 Jardine MJ, Zhou Z, Mahaffey KW, Oshima M, Agarwal R, Bakris G, et al. Renal, cardiovascular, and safety outcomes of canagliflozin by baseline kidney function: a secondary analysis of the CREDENCE randomized trial. J Am Soc Nephrol. 2020;31(5):1128-39.

37 Neuen BL, Young T, Heerspink HJL, Neal B, Perkovic V, Billot L, et al. SGLT2 inhibitors for the prevention of kidney failure in patients with type 2 diabetes: a systematic review and meta-analysis. Lancet Diabetes Endocrinol. 2019 Nov;7(11):845-54.

38 Herrington WG, Preiss D, Haynes R, von Eynatten M, Staplin N, Hauske SJ, et al. The potential for improving cardio-renal outcomes by sodium-glucose co-transporter-2 inhibition in people with chronic kidney disease: a rationale for the EMPA-KIDNEY study. Clin Kidney J. 2018 Dec;11(6):749-61.

39 Liu J, Li L, Li S, Jia P, Deng K, Chen W, et al. Effects of SGLT2 inhibitors on UTIs and genital infections in type 2 diabetes mellitus: a systematic review and meta-analysis. Sci Rep. 2017 Jun 6;7(1):2824.

40 Li D, Wang T, Shen S, Fang Z, Dong Y, Tang H. Urinary tract and genital infections in patients with type 2 diabetes treated with sodium-glucose co-transporter 2 inhibitors: a meta-analysis of randomized controlled trials. Diabetes Obes Metab. 2017 Mar;19(3):348-55.

41 Danne T, Garg S, Peters AL, Buse JB, Mathieu C, Pettus JH, et al. International consensus on risk management of diabetic ketoacidosis in patients with type 1 diabetes treated with Sodium-Glucose Cotransporter (SGLT) inhibitors. Diabetes care. 2019 Jun;42(6):1147-54.

42 Goldenberg RM, Gilbert JD, Hramiak IM, Woo VC, Zinman B. Sodium-glucose co-transporter inhibitors, their role in type 1 diabetes treatment and a risk mitigation strategy for preventing diabetic ketoacidosis: the STOP DKA protocol. Diabetes Obes Metab. 2019 Oct;21(10):2192-202.

43 Matthews DR, Li Q, Perkovic V, Mahaffey KW, de Zeeuw D, Fulcher G, et al. Effects of canagliflozin on amputation risk in type 2 diabetes: the CANVAS program. Diabetologia. 2019 Jun;62(6):926-38.

44 Zhou Z, Jardine M, Perkovic V, Matthews DR, Mahaffey KW, de Zeeuw D, et al. Canagliflozin and fracture risk in individuals with type 2 diabetes: results from the CANVAS program. Diabetologia. 2019 Oct;62(10):1854-67.

45 Arnott C, Huang Y, Neuen BL, Di Tanna GL, Cannon CP, Oh R, et al. The effect of canagliflozin on amputation risk in the CANVAS program and the CREDENCE trial. Diabetes Obes Metab. 2020 May 21.

46 Davies MJ, D’Alessio DA, Fradkin J, Kernan WN, Mathieu C, Mingrone G, et al. Management of hyperglycaemia in type 2 diabetes, 2018. A consensus report by the American Diabetes Association (ADA) and the European Association for the Study of Diabetes (EASD). Diabetologia. 2018 Dec;61(12):2461-98.

47 American Diabetes Association. 9. Pharmacologic approaches to glycemic treatment: standards of medical care in diabetes: 2019. Diabetes Care. 2019;42(Suppl 1):S90-102. 